\title{
COMPARATIVE STUDY OF ROUTINE VERSUS RESTRICTED USE OF EPISIOTOMY IN PRIMIGRAVIDAS
}

\author{
Apurva1 ${ }^{1}$ Sanjay Patil2, Yamini Patil ${ }^{3}$, Rajshree Bhosle 4
}

${ }^{1}$ Resident, Department of Obstetrics and Gynaecology, Krishna Institute of Medical Sciences.

${ }^{2}$ Professor, Department of Obstetrics and Gynaecology, Krishna Institute of Medical Sciences.

${ }^{3}$ Assistant Professor, Department of Obstetrics and Gynaecology, Krishna Institute of Medical Sciences.

${ }^{4}$ Senior Resident, Department of Obstetrics and Gynaecology, Krishna Institute of Medical Sciences.

\section{ABSTRACT}

\section{OBJECTIVES}

To compare maternal morbidity in routine versus selective episiotomy in primigravidae.

\section{STUDY DESIGN}

Prospective case control study.

\section{SETTING AND DURATION OF STUDY}

Obstetrics and gynaecology ward of Krishna Institute of Medical Sciences, Karad, from November 2013 to June 2015.

\section{METHODOLOGY}

Deliveries managed with routine use of episiotomy formed the Control Group, while those managed with restricted use of episiotomy formed the Study Group. Exclusion Criteria of our study was multigravida, multiple pregnancies, assisted breech deliveries, non-vertex presentations including malposition, instrumental deliveries and associated systemic diseases, maternal exhaustion, preterm deliveries, foetal macrosomia, PROM and VBAC. Perineal Pain Score was measured in the post-partum period by $100 \mathrm{~mm}$ VAS (visual analog scale). The main outcome measures which causes maternal morbidity was severe perineal trauma (3rd and 4th degree tears). Other outcomes which cause the maternal morbidity in terms of 1st and 2nd perineal tears, presence of perineal pain, haematoma formation and wound dehiscence were also recorded on proforma.

\section{RESULTS}

This study included 200 patients of routine episiotomy and 200 patients of restricted episiotomy. In the study group, $75 \%$ of women had first degree of tear and $22.5 \%$ women had second degree tear without any post-partum haemorrhage and in the control group; 95\% pregnant women had episiotomy without any extension, 10 pregnant women had third degree of tear. During followup, only 2 patients reported dyspareunia in study group, while 3 patients reported faulty wound healing, 1 patient each reported urinary incontinence and anorectal incontinence, also 4 patients reported dyspareunia among control group.

\section{CONCLUSION}

As perineal pain, perineal tears and wound dehiscence and infections were all less frequent in study group, as compared to routine group, also pelvic muscle strength was better in study group, so overall maternal morbidity was less among study group.

\section{KEYWORDS}

Episiotomy, Low Risk Primigravidae, Perineal Tears/Lacerations.

HOW TO CITE THIS ARTICLE: Apurva, Patil S, Patil Y, et al. Comparative study of routine versus restricted use of episiotomy in primigravidas. J. Evolution Med. Dent. Sci. 2016;5(48):3086-3089, DOI: 10.14260/jemds/2016/718.

\section{INTRODUCTION}

Episiotomy, the surgical enlargement of the vaginal orifice by an incision of the perineum during the last part of the second stage of labour is one of the most commonly performed surgical procedures in the world, particularly for nulliparous women. Despite the extensive utilization to date, there has been no strong scientific evidence of its effectiveness. Episiotomy is the most common operation in obstetrics with the exception of cutting and tying the umbilical cord. ${ }^{1}$

Financial or Other, Competing Interest: None.

Submission 07-04-2016, Peer Review 25-05-2016,

Acceptance 31-05-2016, Published 16-06-2016.

Corresponding Author:

Apurva,

IHR Hostel,

Krishna Institute of Medical Sciences

Taluka - Karad-415110,

District-Satara.

E-mail: dr.apurva28@yahoo.co.in

DOI: $10.14260 /$ jemds $/ 2016 / 718$
The best maternal outcome of pregnancy is a normal vaginal delivery with an intact perineum. Episiotomy is the most common obstetric intervention.2 Episiotomy was performed in estimated $35.2 \%$ of all vaginal deliveries in USA and represents the most frequent type of surgery performed on the female population. ${ }^{3}$ The benefits of episiotomy are claimed to be numerous including substitution of straight surgical incision for ragged laceration, prevention of trauma to foetus, reduction of perineal lacerations and prevention of future pelvic relaxation, but episiotomy per se is a predisposing factor of severe perineal lacerations and maternal morbidity. Episiotomy does not reduce the risk of severe perineal laceration and does not have any impact on perinatal mortality and morbidity. ${ }^{4}$ Indications for performing episiotomy during vaginal delivery are a controversial topic required worldwide review. There is increase in up to $300 \mathrm{~mL}$ or more blood loss among the women undergoing episiotomy. ${ }^{5}$ Episiotomy is a common surgical procedure experienced by women in the United States. 
Based on national hospital discharge data for 1999, just over 35 percent of women who gave birth vaginally had an episiotomy performed; the figure was approximately 33 percent in 2000.6 Despite several decades of research, which many interpret as definitive evidence against routine ("Liberal") use of episiotomy, little professional consensus has developed about the appropriateness of routine use. Lack of consensus is illustrated by variation in rates of use, ranging from 13.3 percent to 84.6 percent in one study with a prospectively enrolled low-risk population with an average of 51 percent among spontaneous term births. ${ }^{7}$ Episiotomy does not have any benefit for prevention of faecal and urinary incontinence or pelvic floor relaxation. Pain during intercourse is more common with episiotomy. ${ }^{6}$

The risk of wound infection is higher, observational studies found higher incidence of wound infection after episiotomy than after spontaneous lacerations. The risk of infection is higher in 4th degree perineal tear, particularly because of contamination from rectum. ${ }^{8}$

\section{METHODOLOGY}

A prospective observational cohort study was done for planned primigravidas singleton normal vaginal term deliveries. The study was conducted between Nov 2013 to June 2015 in the Department of Obs and Gynae, Krishna Institute of Medical Sciences University, Karad, Maharashtra, India. Deliveries managed with routine use of episiotomy formed the Control Group, while those manage with restricted use of episiotomy formed the Study Group.

a. Inclusion Criteria of our study was uncomplicated pregnancy, primigravida, singleton gestation, >37 completed wks. gestational age and vertex presentation.

b. Exclusion Criteria of our study was multigravida, multiple pregnancy, assisted breech deliveries, nonvertex presentations including malposition, instrumental deliveries and associated systemic diseases, maternal exhaustion, preterm deliveries, foetal macrosomia, PROM and VBAC.

There were 200 primigravidae in both groups. In control group: episiotomy was given to all primigravidae according to hospital policy. In study group, episiotomy was avoided and was only given when severe perineal trauma was judged to be imminent and/or for foetal distress. Informed and written consent was taken. In Control Group, after preparing patients by standard method, right mediolateral episiotomy was given after infiltrating the perineum with local anaesthesia $(2 \%$ xylocaine). After delivery episiotomy was stitched in layers with chromic catgut No. 1. Vaginal mucosa was stitched with continuous sutures. On 3rd postnatal day, patient was discharged and was called for follow-up on 7 th postnatal day and thereafter in $3^{\text {rd }}$ month for long-term post-partum complications.
In Study Group patients were prepared as in group A, mother and foetus were monitored closely according to standard method. In this group episiotomy was only given when there was foetal distress or severe perineal trauma was imminent, otherwise delivery carried out without episiotomy and patient was shifted to Gynae ward, discharged and called for follow-up as it was mentioned in control group. Perineal Pain Score was measured in the post-partum period by 100 mm VAS (Visual Analog Scale).

(Figure 1) Anchored with the words "not at all" to "very much" with different activities like bed rest, sitting, walking and defecation for 3 days.

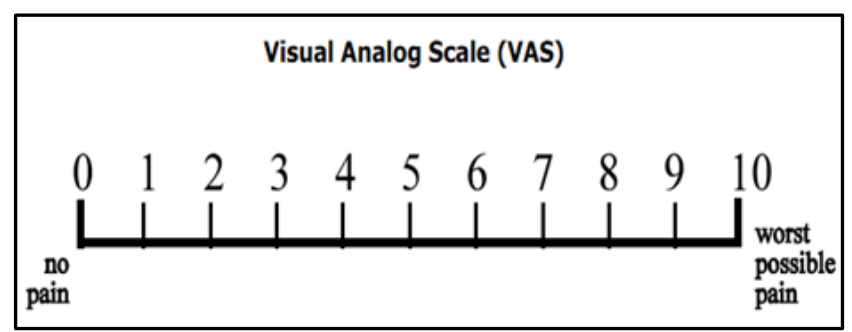

Fig. 1: Visual Analog Scale

In this study, blood loss estimation was done by using single collecting container and fixed sized mops of $10 \times 10 \mathrm{~cm}$. All relevant features including address, phone number, patient's age, gestational age, duration of marriage, antenatal booking status, maternal complications include lacerations/tears, paraurethral tears, perineal pain, postpartum complications and blood loss were recorded on Proforma.

\section{RESULTS}

This study included 200 patients of routine episiotomy and 200 patients of restricted episiotomy. Out of 200 patients of routine episiotomy group, 132 (66\%) were booked and 68 (34\%) were unbooked, while in 200 women of selective episiotomy group 134 (68\%) were booked and 64 (32\%) were unbooked. Data reveals insignificant difference of antenatal booking status between both groups $(\mathrm{p}=0.742)$. The mean age of study group and control group were $23.01 \pm 2.80 \mathrm{yrs}$. and $23.01 \pm 2.80$ yrs. respectively. The difference of mean age between two groups was statistically insignificant $(p=0.792)$. In the study group, $75 \%$ of patients had first degree of tear and $22.5 \%$ patients had second degree tear and without any postpartum haemorrhage in this group (Table 1) and in the control group 95\% patients had episiotomy without any extension, $5 \%$ patients had third degree of tear (Table 2). The third degree tears in study and control group were 3 and 10 patients respectively.

\begin{tabular}{|c|c|c|c|c|c|c|}
\hline Group & $\begin{array}{c}\text { Intact } \\
\text { Perineum }\end{array}$ & $\begin{array}{c}\mathbf{1}^{\text {st }} \\
\text { Degree }\end{array}$ & $\begin{array}{c}\mathbf{2}^{\text {nd }} \\
\text { Degree }\end{array}$ & $\begin{array}{c}3^{\text {rd }} \\
\text { Degree }\end{array}$ & $\begin{array}{c}4^{\text {th }} \\
\text { Degree }\end{array}$ & $\begin{array}{c}\text { Vaginal/ } \\
\text { Labial Tear }\end{array}$ \\
\hline Study & 2 & 150 & 45 & 3 & 0 & 0 \\
\hline Percentage & 1.0 & 75.0 & 22.5 & 1.5 & 0 & 0 \\
\hline \multicolumn{7}{|c|}{ Table 1: Perineal Tear in Study Group (n=200) } \\
\hline
\end{tabular}




\begin{tabular}{|c|c|c|c|}
\hline Group & $\begin{array}{c}\text { (2nd Degree) }^{\text {nd }} \\
\text { Episiotomy Given }\end{array}$ & $\begin{array}{c}\mathbf{3}^{\text {rd }} \\
\text { Degree }\end{array}$ & $\begin{array}{c}\mathbf{4}^{\text {th }} \\
\text { Degree }\end{array}$ \\
\hline Control & 190 & 10 & 0 \\
\hline Percentage & 95.0 & 5.0 & 0 \\
\hline \multicolumn{2}{|c|}{ Table 2: Perineal Tear in Control Group (n=200) } \\
\hline
\end{tabular}

According to VAS, avoiding episiotomy would result in less severe pain immediately, 24 and 48 hours after vaginal delivery compared to routine episiotomy. When comparing two groups (Cases and Control) on maximum pain severity scale (Graph 2) according to Visual Analog Scale (VAS) charts, there was significant difference in post-partum perineal pain perception in routine vs. restrictive episiotomy groups ( $p$ $<0.001$ ).

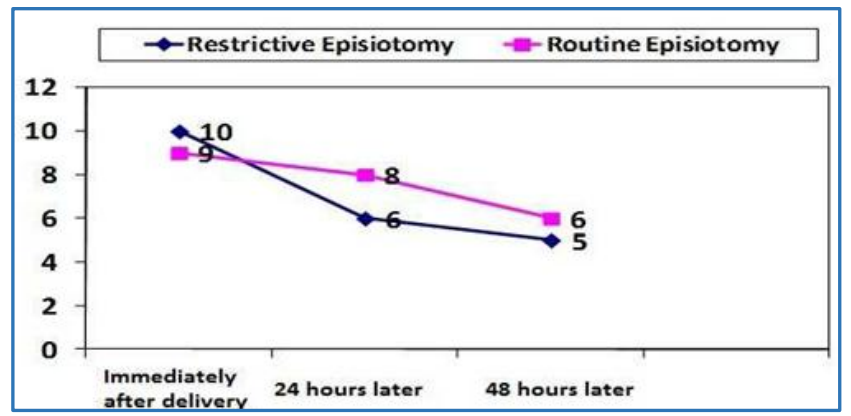

Graph 2: Visual Analog Scale of Study and Control Group

The mean blood loss in episiotomy groups (control) was $341.9 \pm 192.7 \mathrm{~mL}$ and in the case group it was $291.8 \pm 172.3 \mathrm{~mL}$. However, the difference between the two was statistically not significant. Out of 400 cases, ten women had blood loss of $>500$ $\mathrm{mL}$ and 390 women had blood loss of $<500 \mathrm{~mL}$. Blood loss of more than $500 \mathrm{~mL}$ occurred in no woman of study group. In our study, 120 women from study group and 110 women from control group were followed up (Remaining women were lost during follow-up) after three months to know long-term complications. Out of them, 118 women from study group and 101 women from control group reported no complaints during follow-up.

\begin{tabular}{|c|c|c|}
\hline & $\begin{array}{c}\text { Study } \\
\text { Group }\end{array}$ & $\begin{array}{c}\text { Control } \\
\text { Group }\end{array}$ \\
\hline $\begin{array}{c}\text { Number of cases came for } \\
\text { followup }\end{array}$ & 120 & 110 \\
\hline $\begin{array}{c}\text { No. of pts. having no } \\
\text { complications }\end{array}$ & 118 & 101 \\
\hline \multicolumn{2}{|c|}{ Major Complications } \\
\hline Wound gape & 0 & 3 \\
\hline Urinary Incontinence & 0 & 1 \\
\hline Anorectal Incontinence & 0 & 1 \\
\hline Dyspareunia & 2 & 4 \\
\hline Table 3: Postpartum Complications \\
\hline
\end{tabular}

The assessment of pelvic floor muscle strength was done using Oxford Scoring System at the $3^{\text {rd }}$ postpartum month by vaginal palpation in the lithotomy position. Most women in both groups had Oxford Score between 3 and 4 (Table 4).

\begin{tabular}{|c|c|c|}
\hline $\begin{array}{c}\text { Pelvic Floor } \\
\text { Muscle Strength }\end{array}$ & $\begin{array}{c}\text { Study Group } \\
(\mathbf{n = 1 2 0})\end{array}$ & $\begin{array}{c}\text { Control Group } \\
(\mathbf{n = 1 1 0})\end{array}$ \\
\hline 3 & 6 & 10 \\
\hline 4 & 110 & 100 \\
\hline 5 & 4 & - \\
\hline \multicolumn{2}{|c|}{ Table 4: Pelvic Floor Muscle Strength } \\
(In Both the Groups)
\end{tabular}

\section{DISCUSSION}

Episiotomy has been routinely used to facilitate delivery of foetus. Maternal benefits attributed to the use of episiotomy include a reduced risk of perineal trauma, subsequent pelvic floor dysfunction, rectal prolapse, urinary and faecal incontinence and sexual dysfunction. Potential benefits to the foetus were thought to include a shortened second stage of labour resulting from rapid vaginal delivery. ${ }^{7}$ In the study done by Belizan, severe perineal lacerations were uncommon in both groups (Restricted and routine episiotomy), but was slightly less frequent in the restricted group (1.2\% vs $1.5 \%)$, showing that routine episiotomy may cause more perineal trauma. ${ }^{9}$ In our study, primary cause of maternal morbidity was severe perineal lacerations (Third degree perineal tears). Out of 200 patients in control group, third degree perineal tear was seen in $10(6 \%)$ primigravidae, but in study group 3 $(1.5 \%)$ patients had 3rd degree perineal tear.

The findings of our study demonstrated that the rate of maternal short-term complications, such as perineum laceration and pain severity was less in restrictive episiotomy group as compared to routine group. In a similar study in Tehran, Moini A et al,10 reported that total rate of severe perineal tears in routine episiotomy was significantly higher than restrictive episiotomy. They concluded that routine episiotomy is associated with an increased risk of severe perineal tears and subsequent complications especially pain, dyspareunia and incontinence. Similar to Moini et al,10 we found that compared to routine episiotomy, restrictive episiotomy would result in less severe pain immediately, 24 and 48 hours after vaginal delivery.

Although, some studies reported decreased post-delivery pain and dyspareunia using restrictive episiotomy, others disagreed.11,12 The mean blood loss in episiotomy groups (Control) was $341.9 \pm 192.7 \mathrm{~mL}$ and in the case group it was $291.8 \pm 172.3 \mathrm{~mL}$. However, the difference between the two was statistically not significant. In our study, 120 women from study group and 110 women from control group were followed up (Remaining women were lost during follow-up) after three months to know long-term complications.

Out of it only 2 patients reported dyspareunia in study group, while 3 patients reported faulty wound healing, 1 patient each reported urinary incontinence and anorectal incontinence, also 4 patients reported dyspareunia among control group. Sartore A et al concluded from their study that mediolateral episiotomy does not protect against urinary or anal incontinence and genital prolapse. ${ }^{13}$ Belizen study also shows that perineal pain, haematoma formation, wound dehiscence and local infection were more common among routine group as compared to selective group. ${ }^{9}$ Episiotomy is associated with a lower pelvic floor muscle strength compared with spontaneous perineal tears and episiotomy is also associated with more dyspareunia and perineal pain. ${ }^{13}$

In another study in Colombia by Rodriguez et al, the outcome of restricted vs. routine episiotomy for the prevention of third- or fourth degree lacerations in nulliparous women was investigated and the rate of third- or fourth degree perineal lacerations was $14.3 \%$ and $6.8 \%$ in selective and routine episiotomy, respectively. ${ }^{14}$ However, study done by Mora-Hervás et al shows that nulliparous women who had spontaneous deliveries and did not undergo an episiotomy were 9 times more likely to present with a tear (any grade) than those who received an episiotomy [Relative risks (RR) = 
9.6, 95\% CI: 6.3\%-14.6\%, P<0.001]. ${ }^{15}$ In another study, author has concluded that women with intact perineum were pain free after 1.9 weeks, whereas women with second-degree perineal tears recovered after 2.4 weeks and patients with episiotomy recovered from perineal pain after 2.6 weeks. ${ }^{16}$

\section{CONCLUSION}

The purpose of this study was to compare the rate of perineal trauma and tears and whether episiotomy had a protective effect in primiparous women with spontaneous vaginal delivery. In conclusion on the basis of our study, a policy of routine episiotomy should be abandoned in primigravidae instead a restricted episiotomy approach should be followed.

\section{REFERENCES}

1. Pritchard JA, MacDonald PC, Gant NF. Williams' Obstetrics. Norwalk, Appleton-Century-Crofts, 1985;17th ed:p 347.

2. Ali SS, Malik M, Iqbal J, et al. Routine episiotomy versus selective episiotomy in primigravidae. Ann King Edward Med coll 2004;10(4):482-4.

3. Webb DA, Culhane J. Hospital variation in episiotomy use and the risk of perineal trauma during childbirth. Birth 2002;29(2):132-6.

4. Borges BB, Serramo F, Pereira F. Episiotomy-routine versus selective use. Acta Med Port 2003;16(6):447-54.

5. Walysch A, Hallak M. Episiotomy- a review of the literature. Harefuah 2002;141(9):833-8, 856.

6. Hartmann K, Viswanathan M, Palmieri R, et al. Outcomes of routine episiotomy: a systematic review. JAMA 2005;293(17):2141-8.

7. American college of obstetricians and gynaecologists. episiotomy. ACOG practice bulletin no 71. Obstet Gynaecol 2006;107:957-62.
8. Gould D. Perineal tears and episiotomy. Nurs Stand 2007;21(52):41-6.

9. Argentine episiotomy trial collaborative group. Routine vs selective episiotomy a randomized controlled trial. Lanced 1993;342(8886-8887):1517-8.

10. Moini A, Yari RE, Eslami B. Episiotomy and third- and fourth-degree perineal tears in primiparous Iranian women. Int J Gynaecol Obstet 2009;104(3):241-2.

11. Grant A, Gordon B, Mackrodat C, et al. The Ipswich childbirth study: one year follow up of alternative methods used in perineal repair. BJOG 2001;108(1):3440 .

12. Lundquist $\mathrm{M}$, Olsson $\mathrm{A}$, Nissen $\mathrm{E}$, et al. Is it necessary to suture all lacerations after a vaginal delivery? Birth 2000;27(2):79-85

13. Sartore A, De Seta F, Maso G, et al. The effects of mediolateral episiotomy on pelvic floor function after vaginal delivery. Obstet Gynaecol 2004;103(4):669-73.

14. Rodriguez A, Arenas EA, Osorio AL, et al. Selective vs routine midline episiotomy for the prevention of third or fourth-degree lacerations in nulliparous women. Am J Obstet Gynaecol 2008;198(3):285-4.

15. Mora-Hervás, Emília Sánchez, Francisco Carmona, et al. Perineal trauma in primiparous women with spontaneous vaginal delivery: episiotomy or second degree perineal tear? International Journal of Women's Health and Reproduction Sciences 2015;3(2):84-8.

16. Macarthur AJ, Macarthur C. Incidence, severity, and determinants of perineal pain after vaginal delivery: a prospective cohort study. Am J Obstet Gynaecol 2004;191(4):1199-204. 